\title{
A Case of Gorham's Disease with Chylothorax Treated Curatively with Radiation Therapy
}

\author{
Bethany M. Duffy, BA; Rafael Manon, MD; Rakesh R. Patel, MD; and James S. Welsh, MD
}

\begin{abstract}
Gorham's disease, also known as vanishing bone disease or massive osteolysis, is a rare disorder of uncertain etiology. It is characterized by uncontrolled proliferation of vascular or lymphatic capillaries within bone, leading to resorption and replacement with angiomatous tissue. It can be complicated by chylous pericardial and pleural effusions, which can be life threatening. Patients are also at risk of mortality or serious morbidity due to bone destruction, especially when the disease involves the spine. We report the case of a 3I-year-old female with Gorham's disease involving several bones along with chylous pericardial and pleural effusions. She was effectively treated with definitive radiation therapy.
\end{abstract}

Keywords: Essential osteolysis; Chylothorax; Radiotherapy; Bone diseases; Bone resorption; Biopsy

Reprint Requests:

James S. Welsh, MD

University of Wisconsin Cancer Center

410 Dewey Street

Wisconsin Rapids, WI 54494

Tel: $715-42 \mid-7442$

Fax: $715-421-7408$

Email:welsh@humonc.wisc.edu

Received: February 10, 2005

Revised: March 23, 2005

Accepted: March 25, 2005
G orham's disease, also known as vanishing bone disease and massive osteolysis is a very rare disorder of unknown etiology characterized by uncontrolled proliferation of vascular or lymphatic capillaries within bone. ${ }^{1}$ As the endothelial cells proliferate, they aggressively yet painlessly invade the adjacent bone, leading to resorption and replacement with angiomatous tissue. Surrounding soft tissues such as muscle, connective tissue, and viscera may also be affected. Chylous pleural and pericardial effusions can complicate the disease and lead to death in severe cases. In this report, we describe a case of Gorham's disease involving the ribs, scapula, and thoracic spine, which resulted in chylous pericardial and pleural effusions. The patient was treated curatively with radiation therapy.

\section{Case Report}

A female, 31 years of age, presented with a 2-month history of exercise-induced dyspnea. Spirometry was characteristic of reactive airway obstruction, and therefore she was treated for a presumed diagnosis of asthma. Two weeks later she was hospitalized with pleural and pericardial effusions and signs of right ventricular impingement on echocardiogram. The pericardial effusion was drained, yielding 1.5 liters of chocolate-colored fluid consistent with hemo-chylopericardium. Cytology of this fluid identified reactive mesothelial cells and lymphocytes, but was negative for malignancy. Analysis of the pleural 
effusion revealed the same findings. Chest computed tomography (CT) revealed an anterior soft tissue mass and diffuse osteolysis of the right scapula, multiple thoracic and lumbar vertebral bodies, and multiple ribs on the right side. Hodgkin's lymphoma or another metastatic neoplastic process was suspected. However, subsequent biopsy of the mediastinal mass revealed normal thymic tissue with no evidence of malignancy.

Six days after hospitalization the patient underwent an urgent pericardial window procedure to definitively drain the effusion. No abnormal pathology of the pericardium or removed xiphoid process was found. The chylothorax was initially managed with bilateral chest tube drainage and two attempts at talc pleurodesis, which failed to resolve the effusion.

Approximately 3 weeks into her hospitalization, the patient underwent biopsy of the clinically involved right $3^{\text {rd }}$ and $4^{\text {th }}$ ribs, which identified lymphangiomatosis and confirmed the suspected diagnosis of Gorham's disease. Because the patient's chylothorax persisted, thoracic duct ligation was considered. However, she was felt to be a poor surgical candidate due to extensive lymphatic collateralization and the absence of an obvious source of chylous leakage. She was referred to radiation oncology for primary treatment of her Gorham's disease. She was treated with 15 Gy of $10 \mathrm{MV}$ photons in 10 fractions over a 13-day period to the superior, middle, and inferior mediastinum. After receiving this initial low dose of radiation, the patient's respiratory status improved significantly with no apparent toxicity. A follow-up CT scan 2 weeks later confirmed a significant decrease in the amount of thoracic lymphangiomatosis. Because prior published reports described successful outcomes in patients with Gorham's disease using higher radiation doses, an additional 18 Gy in 10 fractions were delivered to the mediastinum and lower neck, bringing the total mediastinal dose to $33 \mathrm{~Gy}$.

Shortly after completion of radiation therapy, the patient developed radiation pneumonitis, which was successfully controlled with steroids. While her pleural effusions never resolved completely, a gradual decline over the following months was observed, improving her respiratory function such that she was eventually able to resume a regular exercise regimen. Sequential CT scans and bone scans confirmed stabilization of her bony disease. Twenty months after completion of her radiation, the patient developed increased pleural effusions with worsening respiratory symptoms. This was treated with a second course of steroid therapy and antibiotics, which quickly resolved her symptoms. Now nearly 3 years since completion of her radiotherapy, the patient is doing remarkably well with no evidence of disease activity.

\section{Discussion}

Gorham's disease is a very rare disorder characterized by uncontrolled, destructive proliferation of vascular or lymphatic capillaries within bone and surrounding soft tissue. ${ }^{1}$ Most cases occur in children and young adults with no clear inheritance pattern or gender bias, although some authors have found males to be affected more often. ${ }^{2,3}$ Manifestations of Gorham's disease vary depending on the affected site making clinical diagnosis of this uncommon disease difficult. Generally, laboratory studies are within normal limits, but radiographic and histopathologic findings are distinct and helpful in making the diagnosis.

Radiographically, Gorham's disease progresses through four stages. ${ }^{4}$ The disease initially presents as radiolucent foci resembling patchy osteoporosis. Next, bony deformity increases with further loss of bone mass. The cortex is then disrupted with endothelial invasion into adjacent soft tissues and/or across joints. Finally, there is shrinkage of the ends of affected bones producing a "sucked candy" appearance. Pathological fracture may develop at any stage, and bony regeneration is rarely seen. The diagnosis of Gorham's disease must be confirmed by identifying vascular or lymphatic proliferation in early stages or fibrous tissue in late stages with a generous biopsy of the affected bone. 1,5

The natural history of Gorham's disease is unpredictable with spontaneous regression being known to occur. 3,6 However, in many patients the disease is relentlessly progressive and involvement of vital structures may be fatal. Several therapeutic modalities have been utilized, including radiotherapy, ${ }^{7-9}$ surgical resection, ${ }^{7,10-12}$ bone grafting, ${ }^{13}$ sympathectomy, ${ }^{14}$ and $\alpha$-interferon. ${ }^{15}$ Recently, most patients have been treated with surgery and/or radiation therapy.

While Gorham's disease has been reported throughout the body, commonly involved sites include the mandible (15\%), ribs $(12 \%)$, scapula $(10 \%)$, humerus $(8 \%)$, pelvis $(10 \%)$, and femur $(11 \%){ }^{3}$ Disease of the ribs, scapula, or thoracic vertebrae leads approximately $17 \%$ of patients to develop chylothorax from direct extension of lymphangiectasia into the pleural cavity or invasion of the thoracic duct. ${ }^{16}$ This can have serious consequences, including hypoproteinemia, malnutrition, and immunosuppression with lymphocytopenia. ${ }^{16,17}$ Without surgical intervention, patients with Gorham's disease who develop chylothorax have a mortality rate of approximately $64 \%$. Tie and colleagues ${ }^{16}$ recently reported some success using thoracic duct ligation to treat chylothorax in Gorham's disease patients. Of the eleven cases they reviewed, seven patients underwent successful thoracic duct ligation and survived, while four patients died following failed attempts to localize the thoracic duct during surgery. This intervention thus improved the survival rate from $36 \%$ to $64 \%$.

However, thoracic duct ligation does not always produce lasting resolution of chylothorax ${ }^{3,17}$ and not all patients are 
good candidates for the procedure. Our patient, for example, was determined to be a poor candidate due to extensive lymphatic collateralization with no clear source of chylous leakage. Other treatment modalities used in Gorham's disease patients with chylothorax have included pleurodesis, ${ }^{10,18-20}$ pleurectomy, ${ }^{21,22} \alpha$-interferon, ${ }^{15}$ and radiation therapy. $8,9,20$

For patients with Gorham's disease with or without chylothorax, radiation therapy has been used with mixed success. $2,8,9,11,20,23-26$ Using escalating doses of radiation to treat Gorham's disease assists in the eradication of increasing numbers of radiosensitive proliferating endothelial cells. ${ }^{26}$ Once an adequate dose has been reached, clones derived from remaining viable cells are spaced too irregularly to form an occlusive vessel. Moderate doses of 25-45 Gy have been reported as effective. ${ }^{7,24}$ After reviewing the 22 published cases of Gorham's disease treated with radiotherapy prior to 1993, Dunbar and colleagues 7 concluded that doses of $40-45$ Gy at 1.8 Gy to 2 Gy per fraction produce a good outcome in a high proportion of patients with minimal long-term complications. Radiation therapy was successful in 14 of the 22 patients (64\%) described in their review.

Prior to 1994, there were no reported cases of Gorham's syndrome with chylothorax treated effectively with radiation. ${ }^{16}$ In 1996, McNeil and colleagues ${ }^{8}$ reported a case treated with 40 Gy in 20 fractions, resulting in resolution of the chylothorax and arrest of bony destruction over 4 years of follow-up. In 2003, Fontanesi ${ }^{9}$ reported another case treated with 40 Gy in 20 fractions, which also achieved a curative result at 6 months of follow-up. Our patient received 33 Gy in 28 fractions and is currently without evidence of disease activity at nearly 3 years since completion of therapy.

There are several potential advantages of using radiation to treat Gorham's disease. Early use of radiation therapy may arrest endothelial cell proliferation, and thereby limit the spread of disease and allow the patient to avoid relatively complicated surgery with its inherent risks. ${ }^{7,26}$ Radiation therapy may also be used successfully in patients who are poor surgical candidates, such as the patient presented in this report, and patients who have failed surgical treatments. Finally, there have been reports of recalcification of affected bone following radiation therapy, a phenomenon that is exceedingly rare with other treatment modalities. A literature review conducted by Choma et al. ${ }^{3}$ in 1987 identified 18 cases of Gorham's disease treated with radiotherapy, 11 of whom showed arrest or improvement of their disease and 5 with demonstrated regrowth of bone. One other patient in their review regenerated bone after treatment with splinting alone. Recently, an additional report of recalcification after radiation therapy was published. ${ }^{27}$

The major disadvantage to using radiation therapy for Gorham's disease is the possibility for acute and long-term side effects that vary by treatment site. Our patient developed radiation pneumonitis that required treatment with steroids. While severe radiation-induced side effects are rare, the potential for secondary malignancy and growth restriction should be considered before administering high-dose radiation therapy to children, who represent a significant proportion of Gorham's disease patients.

In conclusion, because spontaneous resolution has been described in Gorham's disease, it is difficult to prove conclusively that any treatment modality has been curative in a given patient. However, radiation therapy has been documented to produce temporary or long-lasting arrest of osteolysis and symptomatic relief in numerous case reports over the years. In patients with chylothorax secondary to Gorham's disease, radiation can be used as primary therapy or with thoracic duct ligation to halt the progression of osteolysis and provide the potential for regrowth of bone.

\section{References}

1. Gorham WL, Stout AP. Massive osteolysis (acute spontaneous absorption of bone, phantom bone, disappearing bone): its relation to hemangiomatosis. J Bone Joint Surg 1955;37A:985-1004.

2. Heffez L, Doku HC, Carter BL, Feeney JE. Perspectives on massive osteolysis. Report of a case and review of the literature. Oral Surg Oral Med Oral Pathol 1983;55:331-343.

3. Choma ND, Biscotti CV, Bauer TW, Mehta AC, Licata AA. Gorham's syndrome: a case report and review of the literature. Am J Med 1987;83:1151-1156.

4. Torg JS, Steel HH. Sequential roentgenographic changes occurring in massive osteolysis. J Bone Joint Surg Am 1969;51:1649-1655.

5. Ross JL, Schinella R, Shenkman L. Massive osteolysis. An unusual cause of bone destruction. Am J Med 1978;65:367-372.

6. Campbell J, Almond HG, Johnson R. Massive osteolysis of the humerus with spontaneous recovery. J Bone Joint Surg Br $1975 ; 57: 238-240$.

7. Dunbar SF, Rosenberg A, Mankin H, Rosenthal D, Suit HD. Gorham's massive osteolysis: the role of radiation therapy and a review of the literature. Int J Radiat Oncol Biol Phys 1993;26:491-497.

8. McNeil KD, Fong KM, Walker QJ, Jessup P, Zimmerman PV. Gorham's syndrome: a usually fatal cause of pleural effusion treated successfully with radiotherapy. Thorax 1996;51:1275-1276.

9. Fontanesi J. Radiation therapy in the treatment of Gorham disease. J Pediatr Hematol Oncol 2003;25:816-817.

10. Feigl D, Seidel L, Marmor A. Gorham's disease of the clavicle with bilateral pleural effusions. Chest 1981;79:242-244.

11. Gutierrez RM, Spjut HJ. Skeletal angiomatosis: report of three cases and review of the literature. Clin Orthop Relat Res 1972;85:82-97.

12. Turra S, Gigante C, Scapinelli R. A 20-year follow-up study of a case of surgically treated massive osteolysis. Clin Orthop Relat Res 1990;(250):297-302.

13. Woodward HR, Chan DP, Lee J. Massive osteolysis of the cervical spine. A case report of bone graft failure. Spine 1981;6:545-549.

14. King DJ. A case resembling hemangiomatosis of the lower extremity. J Bone Joint Surg 1946;28:623-628.

15. Hagberg H, Lamberg K, Astrom G. Alpha-2b interferon and oral clodronate for Gorham's disease. Lancet 1997;350:1822-1823.

16. Tie ML, Poland GA, Rosenow EC 3rd. Chylothorax in Gorham's syndrome. A common complication of a rare disease. Chest 1994;105:208-213. 
17. Fujiu K, Kanno R, Suzuki H, Nakamura N, Gotoh M. Chylothorax associated with massive osteolysis (Gorham's syndrome). Ann Thorac Surg 2002;73:1956-1957.

18. Patrick JH. Massive osteolysis complicated by chylothorax successfully treated by pleurodesis. J Bone Joint Surg Br 1976;58:347-349.

19. Hejgaard N, Olsen PR. Massive Gorham osteolysis of the right hemipelvis complicated by chylothorax: a report of a case in a 9-year-old boy successfully treated by pleurodesis. J Pediatr Orthop 1987;7:96-99.

20. Lee WS, Kim SH, Kim I, Kim HK, Lee KS, Lee SY, Heo DS, Jang BS, Bang YJ, Kim NK. Chylothorax in Gorham's disease. J Korean Med Sci 2002;17:826-829.

21. Pedicelli G, Mattia P, Zorzoli AA, Sorrone A, De Martino F, Sciotto V. Gorham syndrome. JAMA 1984;252:1449-1451.

22. Miller GG. Treatment of chylothorax in Gorham's disease: a case report and literature review. Can J Surg 2002;45:381-382.

23. Ricalde P, Ord RA, Sun CC. Vanishing bone disease in a five year old: report of a case and review of the literature. Int $\mathrm{J}$ Oral Maxillofac Surg 2003;32:222-226.

24. Heyden G, Kindblom LG, Nielsen JM. Disappearing bone disease. A clinical and histological study. J Bone Joint Surgery Am 1977;59:57-61.

25. Lee S, Finn L, Sze RW, Perkins JA, Sie KC. Gorham Stout syndrome (disappearing bone disease): two additional case reports and a review of the literature. Arch Otolaryngol Head Neck Surg 2003;129:1340-1343.

26. Handl-Zeller L, Hohenberg G. Radiotherapy of Morbus Gorham-Stout: the biological value of low irradiation dose. Br J Radiol 1990;63:206-208.

27. Mawk JR, Obukhov SK, Nichols WD, Wynne TD, Odell JM, Urman SM. Successful conservative management of Gorham disease of the skull base and cervical spine. Childs Nerv Syst 1997;13:622-625.

\section{Author Affiliations}

Bethany M. Duffy, BA, University of Wisconsin Medical

School, Madison, WI 53792.

Rafael Manon, MD and Rakesh R. Patel, MD, Department of Human Oncology, University of Wisconsin, Madison, WI 53792

James S. Welsh, MD, Department of Human Oncology,

University of Wisconsin, Madison, WI 53792, and

University of Wisconsin Cancer Center, 410 Dewey Street,

Wisconsin Rapids, WI 54494 